\title{
Effects of hydrolysed casein, intact casein and intact whey protein on energy expenditure and appetite regulation: a randomised, controlled, cross-over study
}

\author{
Line Q. Bendtsen ${ }^{1}$, Janne K. Lorenzen ${ }^{1}$, Sisse Gomes ${ }^{1}$, Bjørn Liaset ${ }^{2}$, Jens J. Holst ${ }^{3}$, Christian Ritz ${ }^{1}$, \\ Søren Reitelseder ${ }^{4}$, Anders Sjödin ${ }^{1}$ and Arne Astrup ${ }^{1}$ \\ ${ }^{1}$ Department of Nutrition, Exercise and Sports, Faculty of Science, University of Copenhagen, Rolighedsvej 30 , \\ DK-1958 Frederiksberg C, Copenhagen, Denmark \\ ${ }^{2}$ National Institute of Nutrition and Seafood Research, Bergen, Norway \\ ${ }^{3}$ Department of Biomedical Sciences, The NNF Center for Basic Metabolism Research, University of Copenhagen, \\ Copenhagen, Denmark \\ ${ }^{4}$ Institute of Sports Medicine, Bispebjerg Hospital, Copenhagen, Denmark
}

(Submitted 19 January 2014 - Final revision received 26 June 2014 - Accepted 27 June 2014 - First published online 5 September 2014)

\begin{abstract}
Casein and whey differ in amino acid composition and in the rate of absorption; however, the absorption rate of casein can be increased to mimic that of whey by exogenous hydrolysis. The objective of the present study was to compare the effects of hydrolysed casein (HC), intact casein (IC) and intact whey (IW) on energy expenditure (EE) and appetite regulation, and thereby to investigate the influence of amino acid composition and the rate of absorption. In the present randomised cross-over study, twenty-four overweight and moderately obese young men and women consumed three isoenergetic dietary treatments that varied in protein source. The study was conducted in a respiration chamber, where EE, substrate oxidation and subjective appetite were measured over $24 \mathrm{~h}$ at three independent visits. Moreover, blood and urine samples were collected from the participants. The results showed no differences in $24 \mathrm{~h}$ and postprandial EE or appetite regulation. However, lipid oxidation, estimated from the respiratory quotient (RQ), was found to be higher after consumption of IW than after consumption of HC during daytime $(P=0.014)$ as well as during the time after the breakfast meal $(P=0.008)$ when the food was provided. Likewise, NEFA concentrations were found to be higher after consumption of IW than after consumption of HC and IC $(P<0 \cdot 01)$. However, there was no overall difference in the concentration of insulin or glucagon-like peptide 1 . In conclusion, dietary treatments when served as high-protein mixed meals induced similar effects on EE and appetite regulation, except for lipid oxidation, where RQ values suggest that it is higher after consumption of IW than after consumption of HC.
\end{abstract}

Key words: Dairy proteins: Energy expenditure: Substrate oxidation: Appetite

Evidence supports that isoenergetic meals with a high proportion of dietary energy from protein are more satiating ${ }^{(1,2)}$ and stimulate diet-induced thermogenesis (DIT) ${ }^{(3)}$ to a greater extent than energy intake from carbohydrate (CHO) and fat; consequently, intake of high-protein meals may lead to weight loss or reduce body-weight gain over time ${ }^{(4-6)}$. Proteins have unique characteristics related to their content of amino acids, structure and rate of absorption and digestion. Therefore, it is speculated that different proteins have diverse metabolic effects ${ }^{(7,8)}$, and some studies have suggested that they differ in their effects on appetite ${ }^{(3,8-10)}$ and energy expenditure $(\mathrm{EE})^{(3,11)}$.
In many Western countries, dairy products are a major source of dietary protein, and two recent meta-analyses have shown that intake of dairy products combined with energy restriction, but not combined with ad libitum diets, may favour weight loss ${ }^{(12,13)}$. Casein and whey are the major proteins found in dairy products. They differ in the way they are digested and absorbed. Whey is absorbed rapidly and induces a high transient rise in the levels of plasma amino acids, whereas casein coagulates in the acidic environment in the stomach, delaying gastric emptying with a subsequent slower and prolonged rise in the levels of plasma amino acids $^{(14)}$. Moreover, whey and casein differ in their amino

Abbreviations: CHO, carbohydrate; DIT, diet-induced thermogenesis; E\%, percentage of energy; EE, energy expenditure; ER, energy requirements; GLP-1, glucagon-like peptide 1; HC, hydrolysed casein; IC, intact casein; IW, intact whey; RQ, respiratory quotient.

* Corresponding author: L. Q. Bendtsen, fax + 453533 2483, email lbe@life.ku.dk 
acid composition, and some studies have found that whey is more satiating than casein $^{(9,15)}$, but the results have been inconsistent $^{(3,8,16)}$. Likewise, there is no clear evidence that one dairy protein is superior to the other when their effects are examined on $\mathrm{EE}^{(3,8,16,17)}$

The absorption rate of proteins can be manipulated through exogenous hydrolysis, and the absorption rate of hydrolysed casein has been found to be more rapid than that of intact casein and to approach the absorption rate of whey ${ }^{(18,19)}$. Hydrolysis of proteins, especially casein, may consequently affect metabolic parameters. A recent study in mice has demonstrated that consumption of hydrolysed casein reduced body weight and fat mass, partly through increased $\beta$-oxidation in white adipose tissue, compared with consumption of intact casein ${ }^{(20)}$. Moreover, it has been observed that hydrolysed casein tend to induce a lower respiratory quotient (RQ) than intact casein ${ }^{(20)}$. To our knowledge, the satiating effects of casein and its hydrolysate on appetite and EE have not been previously compared in human subjects, while few studies have investigated the satiating effects of whey and its hydrolysate. From these studies, it has been concluded that hydrolysed and intact whey induce similar effects on appetite ${ }^{(21,22)}$, which is supported by similar absorption rates found by Calbet \& Holst ${ }^{(18)}$. However, this finding is not consistent, as Morifuji et al. ${ }^{(23)}$ found that hydrolysed whey is absorbed more rapidly than intact whey. Therefore, whether whey, casein and its hydrolysate have different effects on appetite regulation and $\mathrm{EE}$, as well as the potential mechanisms underlying such possible differences remain to be elucidated.

The objective of the present study was to compare the effects of hydrolysed casein, intact casein and intact whey on $\mathrm{EE}$ and appetite regulation, and thereby to investigate the influence of amino acid composition and the rate of absorption. On the basis of the expected differences in absorption rates, we hypothesised that whey and hydrolysed casein would be more satiating and have a greater effect on EE shortly after protein consumption, whereas intact casein would be more satiating and have a greater thermogenic effect several hours after protein consumption. Moreover, we hypothesised that whey would have a more satiating effect than hydrolysed casein due to its higher protein quality. Finally, we expected that consumption of hydrolysed casein would result in greater lipid oxidation than consumption of intact casein, as observed previously in mice ${ }^{(20)}$.

\section{Subjects and methods}

\section{Subjects}

A total of thirty-six overweight to moderately obese (BMI $27-35 \mathrm{~kg} / \mathrm{m}^{2}$ ) men and women aged 22-40 years were recruited for the study by advertisements at local educational institutions and through web pages from October 2012 to July 2013. All subjects participated in a medical screening, and thirty-three subjects were selected for the study based on the following criteria: healthy; no food allergies; nonvegetarians; non-smokers; no drug abuse; low-to-moderate alcohol consumption; physically active $<10 \mathrm{~h} /$ week; no use of medication (except for contraceptives); no blood donation 3 months before the study; no participation in other clinical studies 4 weeks before the study; $\mathrm{Hb}$ level $>8 \mathrm{mmol} / \mathrm{l}$; fasting blood glucose concentration $<6.1 \mathrm{mmol} / \mathrm{l}$; non-pregnant and non-lactating women. Moreover, all subjects had a stable weight at baseline $( \pm 3 \mathrm{~kg}$ within the previous 3 months $)$, and were instructed not to change their dietary patterns and activity levels throughout the study period. Of the total subjects, seven dropped out between the screening period and the initiation of the study as they could not fit the experimental visits into their schedules, and two were excluded at their first visit due to illness. Finally, twenty-four subjects completed the study. The baseline characteristics of the study participants are presented in Table 1.

The present study was conducted according to the guidelines laid down in the Declaration of Helsinki II, and all procedures involving human subjects were approved by the Danish National Committee on Health Research Ethics. Written informed consent was obtained from all subjects after verbal and written information about the study procedures. The study was registered at ClinicalTrials.gov as NCT01677273.

\section{Experimental design}

The present study was a randomised, double-blind, three-way cross-over trial. All men were tested with at least 2 weeks between the visits, whereas women had to be in the same phase of their menstrual cycle at each visit. The subjects received the following three dietary treatments in a random and balanced order: (1) hydrolysed casein (HC, Hyvital Casein CMA 500; Friesland Campina Domo) with a degree of hydrolysis of $37 \%$; (2) intact casein (IC, Miprodan ${ }^{\circledR} 30$; Arla Foods Amba); (3) intact whey (IW, Lacprodan ${ }^{\circledR}$ SP-9225 Instant; Arla Foods Ingredients).

Each intervention visit lasted $40 \mathrm{~h}$, during which the subjects spent $25 \mathrm{~h}$ in a respiration chamber (Fig. 1). The subjects were asked to consume a standardised meal (17\% of energy (E\%) from protein, $50 \mathrm{E} \%$ from $\mathrm{CHO}$ and $33 \mathrm{E} \%$ from fat) at home

Table 1. Characteristics of the study subjects at baseline (Mean values and standard deviations, $n$ 24)

\begin{tabular}{|c|c|c|}
\hline Characteristics & Mean & $\mathrm{SD}$ \\
\hline \multicolumn{3}{|l|}{$\operatorname{Sex}(n)$} \\
\hline Male & & \\
\hline Female & & \\
\hline Age (years) & 29 & 6 \\
\hline Body weight $(\mathrm{kg})$ & $95 \cdot 6$ & $10 \cdot 1$ \\
\hline Height $(\mathrm{cm})$ & $178 \cdot 0$ & 8.5 \\
\hline BMI $\left(\mathrm{kg} / \mathrm{m}^{2}\right)$ & $30 \cdot 1$ & $2 \cdot 3$ \\
\hline Fat-free mass $(\mathrm{kg})^{\star}$ & $63 \cdot 8$ & $10 \cdot 1$ \\
\hline Fat mass $(\mathrm{kg})^{*}$ & $31 \cdot 7$ & $8 \cdot 7$ \\
\hline Fat mass $(\%)^{*}$ & $33 \cdot 1$ & $8 \cdot 6$ \\
\hline Systolic blood pressure (mmHg) & 126 & 11 \\
\hline Diastolic blood pressure $(\mathrm{mmHg})$ & 79 & 9 \\
\hline Fasting plasma glucose $(\mathrm{mmol} / \mathrm{l})$ & $5 \cdot 1$ & 0.4 \\
\hline
\end{tabular}

*Body composition was determined by dual-energy X-ray absorptiometry. 

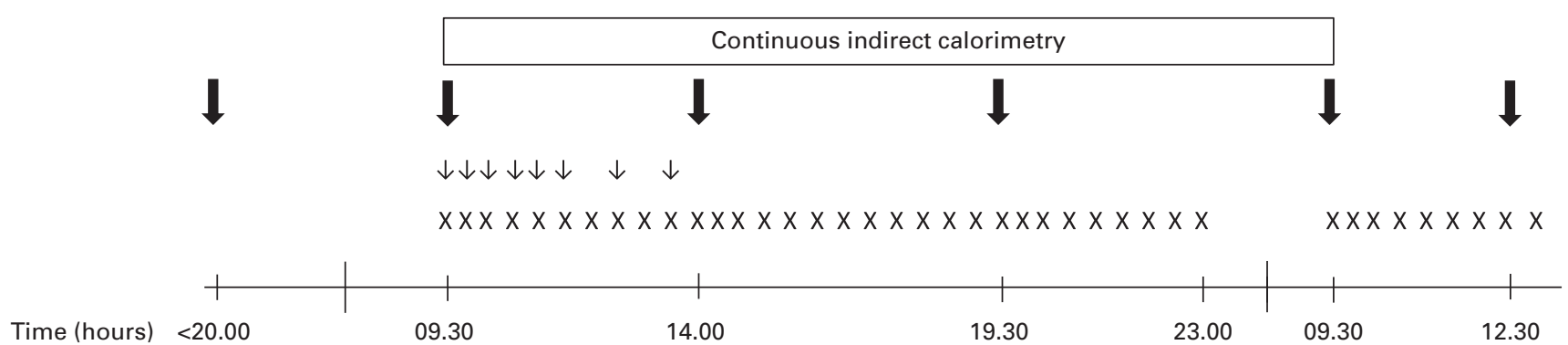

Fig. 1. Experimental design. All twenty-four subjects made three visits during the study period. $\downarrow$, Meals/proteins; $\downarrow$, biochemical measures; $X$, visual analogue scales.

no later than 20.00 hours and to arrive at the metabolic research unit at 22.00 hours on day 0 . They slept in the respiration chamber (with doors opened) to acclimatise to the environment. At 07.30 hours on day 1 , the subjects were awakened and weighed after emptying their bladder in order to confirm weight stability during the study. Moreover, a Venflon catheter (Venflon ${ }^{\mathrm{TM}}$ Pro I.V. Cannula; Becton Dickinson) was placed in an antecubital vein for blood sampling at the following time points after 09.30 hours on day 1: $0,15,30,60,90$, 120,180 and $240 \mathrm{~min}$. At 08.30 hours on day 1, the respiration chamber was closed to ensure that the subjects were in a steady state when measurements were started at 09.30 hours. The chamber remained closed until 09.30 hours on day 2. During the stay in the respiration chamber, subjective appetite assessments, biochemical measures, respiratory gas exchange measures and $24 \mathrm{~h}$ urine collection were obtained as described in detail below. Blood samples for biochemical measures were collected through airtight locks. On day 2, the subjects were served breakfast at 09.30 hours, and appetite was assessed until the intervention visit ended with an ad libitum lunch meal at 12.30 hours.

\section{Physical examination}

Physical examination conducted at the screening visit included measurements of body weight, height and blood pressure. Body weight was recorded to the nearest $0 \cdot 1 \mathrm{~kg}$ (Lindeltronic 8000S; Lindells), and height was measured to the nearest $0.5 \mathrm{~cm}$ with a wall-mounted stadiometer. Body composition was determined by dual-energy X-ray absorptiometry (Lunar Radiation Company). Systolic and diastolic blood pressure measurements were recorded by an automatic device (A \& D Instruments Limited) after a 5-10 min rest in a supine position. All measurements were made with subjects wearing only underwear and after a $12 \mathrm{~h}$ fast.

\section{Diets}

All meals served included a protein shake containing one of the three dietary treatments of interest: HC; IC; IW. Energy density, macronutrient composition and fibre content were similar between the three dietary treatments. Daily energy requirements (ER) were calculated based on fat-free mass $^{(24)}$, with a physical activity factor of 1.4 representing a sedentary lifestyle.

Resting energy expenditure $=370+21.6 \times$ fat-free mass,

$$
24 \mathrm{~h} \mathrm{ER}=\text { resting energy expenditure } \times 1.4 .
$$

The subjects received $3 \mathrm{~g} / \mathrm{MJ}$ required/d of added protein (HC, IW or IC) in each shake (corresponding to approximately $30 \mathrm{~g}$ of protein per shake in a diet containing $10 \mathrm{MJ}$ ). Each shake contained $26 \mathrm{E} \%$ from protein, where HC, IW or IC contributed to $22.3 \mathrm{E} \%$ in the respective shakes. The amino acid composition of the three proteins is presented in Table 2. Unfortunately, it was not possible to use a casein hydrolysate manufactured from the intact casein provided, and analyses showed that the amount of some of the potentially important amino acids deviated between $\mathrm{HC}$ and IC. Consequently, single free amino acids (leucine, phenylalanine, proline, tryptophan and tyrosine) were added to $\mathrm{HC}$ in accordance with a predetermined cut-off limit of $\pm 10 \%$ deviation

Table 2. Amino acid composition of hydrolysed casein $(\mathrm{HC})$, intact casein (IC) and intact whey (IW)*

\begin{tabular}{|c|c|c|c|}
\hline Amino acids & $\begin{array}{c}\mathrm{HC} \\
\text { (mg/g protein) } \dagger\end{array}$ & $\begin{array}{c}\text { IC } \\
\text { (mg/g protein) } \ddagger\end{array}$ & $\begin{array}{c}\text { IW } \\
(\mathrm{mg} / \mathrm{g} \text { protein)§ }\end{array}$ \\
\hline Ala & 33.0 & 32.9 & 53.4 \\
\hline Arg & 34.5 & $36 \cdot 4$ & $18 \cdot 6$ \\
\hline Asp & 82.4 & $80 \cdot 6$ & $120 \cdot 6$ \\
\hline Glu & $248 \cdot 2$ & 242.9 & $192 \cdot 6$ \\
\hline Gly & $17 \cdot 2$ & $18 \cdot 1$ & $15 \cdot 1$ \\
\hline His & $27 \cdot 2$ & $27 \cdot 8$ & $17 \cdot 4$ \\
\hline Ile & $51 \cdot 2$ & 52.4 & $68 \cdot 4$ \\
\hline Leu & $96 \cdot 5$ & $98 \cdot 0$ & 111.4 \\
\hline Lys & 88.4 & 86.5 & 104.4 \\
\hline Met & $27 \cdot 8$ & $29 \cdot 3$ & $23 \cdot 2$ \\
\hline Phe & $48 \cdot 3$ & $53 \cdot 7$ & 25.5 \\
\hline Pro & 105.5 & 108.4 & $49 \cdot 9$ \\
\hline Ser & 61.9 & $57 \cdot 2$ & 53.4 \\
\hline Thr & $47 \cdot 0$ & $44 \cdot 1$ & $76 \cdot 6$ \\
\hline Trp & $11 \cdot 6$ & $12 \cdot 5$ & $18 \cdot 6$ \\
\hline Tyr & 48.4 & 54.4 & $30 \cdot 2$ \\
\hline Val & $65 \cdot 3$ & $67 \cdot 6$ & 61.5 \\
\hline
\end{tabular}

* Single free amino acids (Leu, Phe, Pro, Trp and Tyr) were added to HC to match the amino acid composition of IC.

$+80.2 \%$ protein.

$\ddagger 87.9 \%$ protein.

$\S 86.2 \%$ protein. 
between the proteins. On day 1 , the subjects were served three meals at 09.30, 14.00 and 19.30 hours (Fig. 1), contributing to 20,40 and $40 \%$ of ER, respectively. For breakfast, the subjects were served a protein shake $(26 \mathrm{E} \%$ from protein, $50 \mathrm{E} \%$ from $\mathrm{CHO}$ and $24 \mathrm{E} \%$ from fat), but for lunch (18E\% from protein, $57 \mathrm{E} \%$ from $\mathrm{CHO}$ and $25 \mathrm{E} \%$ from fat) and dinner $(17 \mathrm{E} \%$ from protein, $58 \mathrm{E} \%$ from $\mathrm{CHO}$ and $25 \mathrm{E} \%$ from fat), the subjects were provided with additional standardised foods to meet their ER. The subjects were not allowed to drink water ad libitum, but $200 \mathrm{ml}$ of water were served with all meals and, in addition, three times during day 1 . On day 2, the subjects were served a protein shake for breakfast (identical to day 1) and an ad libitum lunch meal (15E\% from protein, $55 \mathrm{E} \%$ from $\mathrm{CHO}$ and $30 \mathrm{E} \%$ from fat) at 12.30 hours, during which period the subjects were asked to eat until they felt comfortably satiated.

\section{Energy expenditure and substrate oxidation}

EE was calculated from respiratory gas exchange measured in two identical respiration chambers ${ }^{(25)}$. The respiration chambers are rooms measuring $14.7 \mathrm{~m}^{3}$ equipped with a bed, desks, chairs, telephone, television, computer and toilet facilities. The room temperature was kept constant at $22.5^{\circ} \mathrm{C}$. Gas exchange was calculated from measured airflow and concentrations of $\mathrm{O}_{2}$ and $\mathrm{CO}_{2}$ at the outlet of the chamber as well as in the fresh air going in. Urine was quantitatively collected for $24 \mathrm{~h}$ in containers with $\mathrm{HCl}$, and protein oxidation was calculated from the amount of urinary $\mathrm{N}$ multiplied by $6 \cdot 25$.

Measurements of $24 \mathrm{~h}$ total EE, RQ and substrate oxidation were made starting from 09.30 hours on day 1 until 09.30 hours on day 2, and presented as postprandial effects after the breakfast meal on day 1 (09.30-14.00 hours) during daytime (09.30-01.00 hours), during night-time (01.00-06.00 hours) and over the total $24 \mathrm{~h}$ period. BMR was assessed from 08.00 to 09.00 hours on day 2 , and sleeping metabolic rate was determined from 01.00 to 06.00 hours on day 2 . The subjects were told to avoid physical activity, but spontaneous physical activity was measured by a microwave radar based on the Doppler principle (Sisor Mini-Radar; Static Input System). Substrate oxidation was calculated from $24 \mathrm{~h}$ urinary $\mathrm{N}, \mathrm{O}_{2}$ consumption and $\mathrm{CO}_{2}$ production. $\mathrm{CHO}$ and lipid oxidation were calculated according to the method described by Elia \& Livesey ${ }^{(26)}$.

\section{Appetite assessment and energy intake}

Visual analogue scales were used to assess subjective appetite sensations as well as palatability of meals. The scales were based on a series of questions presented individually on sheets in a visual analogue scale booklet. They consisted of a $100 \mathrm{~mm}$ horizontal line with words anchored at each end, expressing the most positive and the most negative ratings of hunger, satiety, fullness and prospective food consumption, and desire to eat something fatty, salty, sweet or savoury, and, finally, the palatability of the test meals. On day 1 , visual analogue scales were filled out every $30 \mathrm{~min}$ as well as after each meal (09.40 hours (10 min), 14.15 hours $(285 \mathrm{~min})$ and 19.40 hours $(610 \mathrm{~min})$ ) from 09.30 to 23.00 hours. On day 2, they were filled out every $30 \mathrm{~min}$ and after each meal (09.40 hours and after the ad libitum meal) from 09.30 to 12.30 hours.

Energy intake was assessed from an ad libitum lunch meal served at 12.30 hours on day 2 . The meal consisted of spaghetti Bolognese (15 $\mathrm{E} \%$ from protein, $55 \mathrm{E} \%$ from $\mathrm{CHO}$ and $30 \mathrm{E} \%$ from fat). The subjects were instructed to eat until they felt comfortably satiated. The time spent was selfdetermined, but registered for the analysis of data.

\section{Biochemical measures}

Blood plasma or serum samples were analysed to measure the concentrations of insulin, glucose, total glucagon-like peptide-1 (GLP-1) and NEFA.

Blood samples were drawn into $2 \mathrm{ml}$ sodium fluorideoxalate tubes and $2 \mathrm{ml}$ serum clot activator tubes (Vacuette; Hettich) for analyses of glucose and insulin concentrations, respectively. For analysis of GLP-1 concentration, blood samples were collected into $6 \mathrm{ml}$ EDTA tubes, to which $300 \mu \mathrm{l}$ dipeptidyl peptidase IV inhibitor were added. For analysis of NEFA concentration, blood samples were collected into $4 \mathrm{ml}$ EDTA tubes. The glucose, GLP-1 and NEFA samples were immediately centrifuged for $10 \mathrm{~min}$ at $4^{\circ} \mathrm{C}$ at $2500 \mathrm{rpm}$, pipetted into $2 \mathrm{ml}$ cryotubes and stored at $-80^{\circ} \mathrm{C}$ until further analysis. Before centrifugation, insulin samples were allowed to coagulate for $20-30 \mathrm{~min}$. Serum insulin concentration was quantified by a solid-phase, two-site chemiluminescent immunometric assay (Siemens Healthcare Diagnostics) on an Immulite 1000 analyser. Concentrations of glucose and NEFA were analysed by ABX Pentra 400 (Horiba ABX) and total GLP-1 concentration was analysed by RIA (antiserum no. 89390) (27) $^{\text {. }}$

Finally, $24 \mathrm{~h}$ urinary $\mathrm{N}$ was determined by the Dumas combustion method, using a VarioMax CN analyser (Elementar).

\section{Statistical analyses}

Power calculations were based on previous studies examining protein-induced changes in $\mathrm{EE}^{(11,28,29)}$. With a sensitivity of 0.80 and a significance level of 0.05 , power calculation indicated a sample size of twenty-four when the minimal detectable difference was set to $0 \cdot 22$ with a within-subject standard deviation of $0 \cdot 25$.

Data are presented as means with their standard errors, unless otherwise specified.

Repeated-measures analyses were conducted using linear mixed models to examine the differences between proteins in relation to $\mathrm{EE}$, RQ, substrate oxidation, biochemical measures and subjective appetite. All analyses included adjustment for age, sex and order of intervention, and subjects were included as random effects. Moreover, in the analysis of EE, RQ and substrate oxidation, respiration chambers were additionally included as random effects, and analyses were also controlled for spontaneous physical activity. A two-way ANOVA was used to examine the differences (means with their standard errors) in BMR and ad libitum energy intake between the dietary treatments. Furthermore, associations between insulin and glucose, insulin and GLP-1, insulin and 
lipid oxidation and NEFA and lipid oxidation were explored using Pearson's correlation coefficients.

Repeated-measures analyses were also used to analyse the data on EE, RQ, substrate oxidation, biochemical measures and subjective appetite in the postprandial period after the breakfast meal on day 1 (09.30-14.00 hours). Moreover, data on EE, RQ and substrate oxidation were analysed during daytime (09.30-01.00 hours), during night-time (01.00-06.00 hours) and over the total $24 \mathrm{~h}$ period. BMR values were analysed from 08.00 to 09.00 hours on day 2, and data on subjective appetite were additionally analysed during daytime (09.30-23.00 hours) and after the breakfast meal on day 2 (09.30-12.45 hours).

Finally, peak magnitude and time to peak were analysed to determine the levels of glucose, insulin and GLP-1, and nadir magnitude and time to nadir were analysed to determine the levels of glucose and NEFA.

All statistical models were checked for normality and variance homogeneity, and all data that were non-normally distributed were transformed. Moreover, all multiple pairwise comparisons were Bonferroni-adjusted.

Statistical analyses were performed using the STATA software, version 11.2 (StataCorp LP, 2011), and statistical significance was set at $P<0 \cdot 05$.

\section{Results}

\section{Energy expenditure}

The results revealed that $24 \mathrm{~h}$ EE did not differ from $24 \mathrm{~h}$ energy intake $(10396$ (sEm 255$) \mathrm{kJ} / 24 \mathrm{~h}$ ) and between the dietary treatments (Table 3), which indicates that the subjects remained in energy balance during all the visits. Likewise, there was no difference between the dietary treatments in relation to either the postprandial EE after consumption of the breakfast meal on day 1, daytime EE, sleeping metabolic rate, or BMR after adjustment for spontaneous physical activity (Table 3).

\section{Respiratory quotient and substrate oxidation}

Total protein oxidation in relation to total EE over $24 \mathrm{~h}$ was similar between the dietary treatments (HC 22.2 (SEM 0.7 ) \%, IC $21 \cdot 5$ (SEM $0 \cdot 8) \%$ and IW $22 \cdot 1$ (SEM 0.7) \%).
There was no effect observed for the time $\times$ treatment interaction on the RQ at either time interval studied (after breakfast: $P=0.42$; daytime: $P=0.69 ; 24 \mathrm{~h}: P=0.58$; nighttime: $P=0 \cdot 22)$; however, an effect of treatment was observed during daytime $(P=0.048)$ and after the breakfast meal $(P=0.029)$ on day 1 . The mean postprandial RQ value was 0.02 units higher after consumption of HC than after consumption of IW $(P=0.036)$ during daytime (Fig. 2(a)), as well as during the time after the breakfast meal (0.02 units, $P=0 \cdot 018$ ) on day 1 (Fig. 2(b)), when the food was provided, and these results remained significant after adjustment for $24 \mathrm{~h}$ energy balance. There was no difference in RQ between the dietary treatments during night-time and when calculated over the total $24 \mathrm{~h}$ period.

Accordingly, there was no effect observed for the time $\times$ treatment interaction on either lipid (after breakfast: $P=0.50$; daytime: $P=0.72 ; 24 \mathrm{~h}: P=0.53$; night-time: $P=0.16)$ or $\mathrm{CHO}$ oxidation (after breakfast: $P=0.46$; daytime: $P=0.70 ; 24 \mathrm{~h}$ : $P=0.53$; night-time: $P=0.16$ ) at all time intervals studied. However, an effect of treatment was observed on lipid oxidation during daytime and after the breakfast meal on day 1 (after breakfast: $P=0.008$; daytime: $P=0 \cdot 014$ ). Postprandial lipid oxidation was $13 \%$ higher after ingestion of IW than after ingestion of $\mathrm{HC}$ during daytime $(P=0.036)$ and $15 \%$ higher after ingestion of the breakfast meal on day 1 $(P=0 \cdot 015)$. There was no difference between the HC and IC treatments or between the IW and IC treatments (Fig. 3). Accordingly, an effect of treatment was observed on CHO oxidation after the breakfast meal on day $1(P=0.041)$. It was $18 \%$ lower after ingestion of IW than after ingestion of $\mathrm{HC}$, but did not differ between the HC and IC treatments or between the IW and IC treatments (Fig. 3). There was no difference in substrate oxidation during night-time and during the $24 \mathrm{~h}$ period between the dietary treatments.

\section{Biochemical measures}

There were no significant differences in baseline values for serum insulin and plasma glucose, NEFA and GLP-1 concentrations. Likewise, no effects of the time $\times$ treatment interaction were observed for postprandial serum insulin, plasma glucose or NEFA concentrations (Fig. 4). However, the overall postprandial plasma glucose concentration was higher

Table 3. Energy expenditure

(Mean values with their standard errors)

\begin{tabular}{|c|c|c|c|c|c|c|c|}
\hline & \multicolumn{2}{|c|}{$\mathrm{HC}$} & \multicolumn{2}{|c|}{ IC } & \multicolumn{2}{|c|}{ IW } & \multirow[b]{2}{*}{$P$} \\
\hline & Mean & SEM & Mean & SEM & Mean & SEM & \\
\hline $24 \mathrm{~h} \mathrm{EE}(\mathrm{kJ} / 24 \mathrm{~h})^{\star}$ & 10410 & 252 & 10474 & 271 & 10445 & 266 & NS \\
\hline EE after breakfast on day $1(\mathrm{~kJ} / 4.5 \mathrm{~h})^{\star}$ & 2208 & 55 & 2224 & 58 & 2230 & 56 & NS \\
\hline Daytime EE $(\mathrm{kJ} / 15.5 \mathrm{~h})^{*}$ & 7649 & 197 & 7674 & 205 & 7693 & 205 & NS \\
\hline SMR $(k J / 6 h)^{*}$ & 1642 & 39 & 1669 & 45 & 1635 & 40 & NS \\
\hline BMR $(\mathrm{kJ} / \mathrm{h}) \dagger$ & 382 & 10 & 378 & 11 & 381 & 10 & NS \\
\hline SPA $(\% / 24 h)^{*}$ & 14.4 & 1.3 & $14 \cdot 7$ & 1.3 & 14.4 & $1 \cdot 1$ & NS \\
\hline
\end{tabular}

HC, hydrolysed casein; IC, intact casein; IW, intact whey; EE, energy expenditure; SMR, sleeping metabolic rate; SPA, spontaneous physical activity.

* Data were analysed by a repeated-measures analysis using a mixed linear model.

†BMR was analysed by a two-way ANOVA ( $n$ 24). 

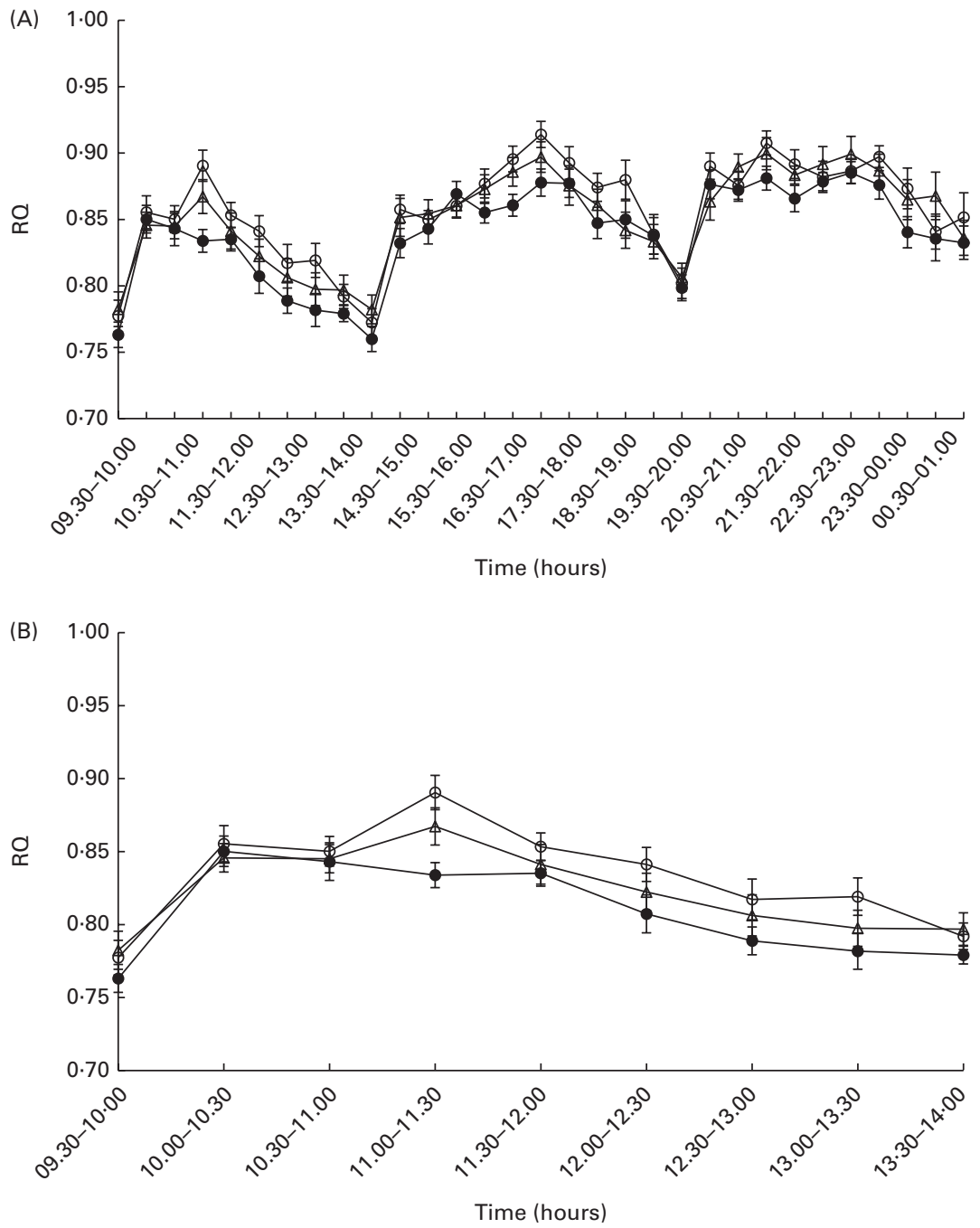

Fig. 2. Postprandial respiratory quotient (RQ) values during daytime (A) and after the breakfast meal (B) on day 1 ( $n$ 24). Values are means, with their standard errors represented by vertical bars. Repeated-measures analyses showed no effect for the time $\times$ treatment interactions (after breakfast: $P=0.42$; daytime: $P=0.69)$, but the $R Q$ value was higher for hydrolysed casein $(-)$ than for intact whey $(-\rightarrow)$ during daytime $(P=0.036)$, as well as during the time after the breakfast meal on day $1(P=0.018)$. $\triangle$, Intact casein.

after ingestion of IC than after ingestion of $\mathrm{HC}(P=0.033)$, with no difference being observed between the HC and IW treatments and between the IW and IC treatments. Moreover, the difference in plasma glucose concentration was not explained by the difference in serum insulin concentration, which was similar after ingestion of all the three dietary treatments. Accordingly, there were no significant differences observed between the dietary treatments in relation to peak magnitude and time to peak for glucose and insulin concentrations, as well as no significant differences between the dietary treatments in relation to nadir magnitude and time to nadir were observed for glucose concentration. On the contrary, nadir magnitude for NEFA concentration was lower after consumption of HC than after consumption of IW $(P<0 \cdot 001)$ and IC $(P=0.003)$, with no significant difference in time to nadir. Furthermore, the mean postprandial concentration of NEFA was higher after consumption of IW than after consumption of HC ( $P=0.003)$ and IC $(P<0.0001)$, with no difference being observed between the HC and IC treatments (Fig. 4). No overall effect of treatments was observed for GLP-1 concentration, but a time $\times$ treatment interaction effect was found $(P=0 \cdot 012)$. At 15 min, GLP-1 concentration was higher after ingestion of IC than after ingestion of $\mathrm{HC}$ and IW $(P<0.05)$ with no difference being observed between the HC and IW treatments. GLP-1 concentration was higher after consumption of $\mathrm{HC}$ than after consumption of IW at 60 and $90 \mathrm{~min}(P=0.042$ and $P=0.015$, respectively) and higher after consumption of $\mathrm{HC}$ than after consumption of IC at $90 \mathrm{~min}(P=0 \cdot 012)$. It did not differ between the IW and IC treatments (Fig. 4), and there were no significant differences observed between the dietary treatments in relation to peak magnitude and time to peak for GLP-1 concentration.

Serum insulin concentration was correlated with plasma GLP-1 ( $r$ 0.3042, $P<0.0001)$ and glucose $(r 0.3519, P<0.0001)$ concentrations. Moreover, NEFA and insulin concentrations 

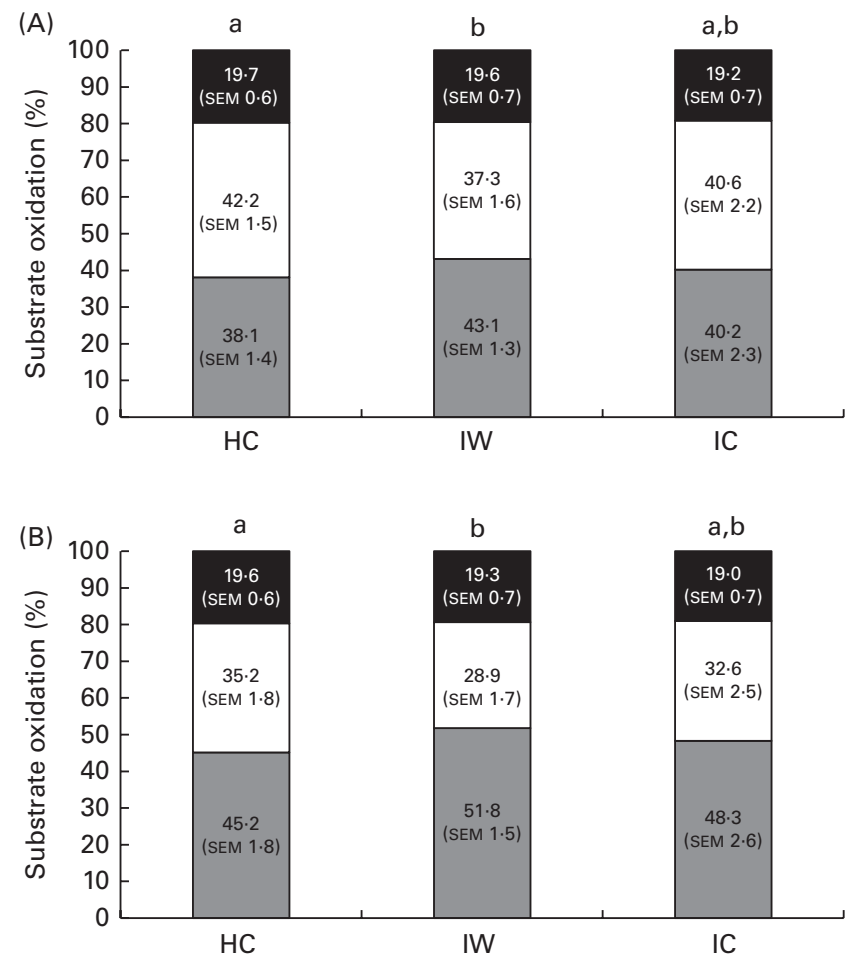

Fig. 3. Substrate oxidation during daytime (A) and after the breakfast meal (B) on day 1 ( $n$ 24). There was no difference in protein oxidation between the dietary proteins. Repeated-measures analyses showed that intact whey (IW) stimulated larger lipid oxidation and smaller carbohydrate oxidation than hydrolysed casein $(\mathrm{HC})$ during daytime as well as during the time after the breakfast meal on day 1 . There was no difference between the $\mathrm{HC}$ and intact casein (IC) treatments or between the IW and IC treatments. Values are means, with their standard errors. ${ }^{\mathrm{a}, \mathrm{b}}$ Mean values with unlike letters were significantly different $(P<0.05)$. $\square$, Lipid; $\square$, carbohydrate; $\square$, protein.

were positively $(r 0 \cdot 4894, P<0 \cdot 0001)$ and negatively $(r-0 \cdot 1813$, $P=0 \cdot 0002)$ correlated, respectively, with lipid oxidation.

\section{Appetite}

There were no effects observed for the time $\times$ treatment interaction and for treatment on satiety, hunger, fullness and prospective food consumption during daytime, as well as during the time after the breakfast meal on day 1 or day 2 . Thirst was also not affected differently by the three dietary treatments at any time intervals studied. However, IC elicited a lower desire to eat savoury foods than IW during daytime $(P=0.006)$, and tended to elicit a lower desire to eat savoury foods after ingestion of the breakfast meal on day 1 $(P=0.075)$. There was no difference observed between the HC and IC treatments or between the HC and IW treatments, as well as between any of the treatments after the breakfast meal on day 2. IC also elicited a lower desire to eat sweet foods than HC after ingestion of the breakfast meal on day 1 $(P=0.015)$ and day $2(P=0.021)$. Moreover, IW tended to induce a lower desire to eat sweet foods than HC after ingestion of the breakfast meal on day $2(P=0 \cdot 087)$. However, there was no difference observed between the dietary treatments during daytime. Likewise, there was no difference observed
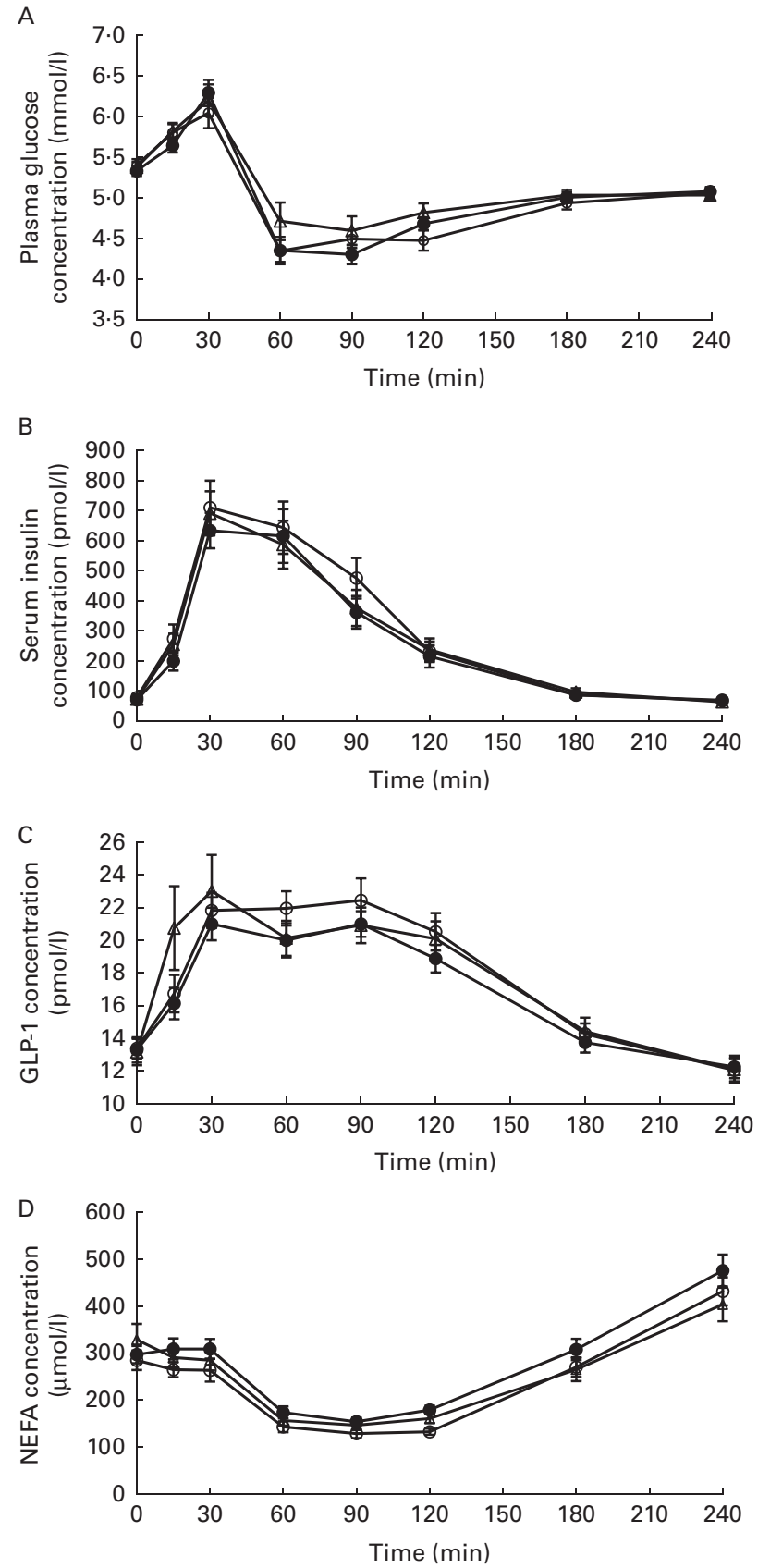

Fig. 4. Response of (A) glucose, (B) insulin, (C) glucagon-like peptide 1 (GLP-1) and (D) NEFA concentrations after ingestion of the breakfast meal on day 1 (0-240 min; $n$ 24). Glucose concentrations were higher after ingestion of intact casein $(\mathrm{IC}, \triangle)$ than after ingestion of hydrolysed casein ( $\mathrm{HC}$ $(\ominus) ; P=0.033$ ); however, there was no difference between the $\mathrm{HC}$ and intact whey (IW,--) treatments or between the IW and IC treatments. No difference was observed in insulin concentrations between the dietary treatments. For GLP-1, there was a significant effect of the time $\times$ treatment interaction. At $15 \mathrm{~min}, \mathrm{GLP}-1$ concentration was higher after ingestion of IC than after ingestion of $\mathrm{HC}$ and IW $(P<0.05)$, with no difference being observed between the $\mathrm{HC}$ and IW treatments. However, at 60 and $90 \mathrm{~min}$, GLP-1 concentration was higher after ingestion of $\mathrm{HC}$ than after ingestion of IW and IC $(P<0.05$ and $P<0.01$, respectively), but did not differ between the IW and IC treatments. There were no significant differences observed at any other time points. The concentration of NEFA was higher after ingestion of IW than after ingestion of $\mathrm{HC}(P=0.003)$ and IC $(P<0.0001)$, with no difference being observed between the $\mathrm{HC}$ and $\mathrm{IC}$ treatments. 
between the dietary treatments in relation to the desire to eat salty or fatty foods at any of the time intervals studied.

Moreover, there was no difference in energy intake observed between the dietary treatments after the ad libitum lunch meal on day 2 (HC: 3571 (SEM 218) kJ; IW: 3780 (SEM 216) kJ; IC: 3667 (SEM 180) kJ), and palatability assessed after the ad libitum meal did not depend on the dietary treatments.

The palatability of the test meals was rated lower after consumption of $\mathrm{HC}$ than after consumption of IW and IC $(P<0.01)$, and an effect of the time $\times$ treatment interaction was found for feelings of comfort $(P=0.038)$. After breakfast, the subjects felt less comfortable after consumption of $\mathrm{HC}$ than after consumption of IW at 10, 30 and $60 \mathrm{~min}(P<0.01)$, and tended to feel less comfortable at $150 \mathrm{~min}(P=0.075)$. Moreover, immediately after the breakfast meal on day 1 (10 min), the subjects felt less comfortable after consumption of HC than after consumption of IC $(P=0.003)$. There was no difference in feelings of comfort observed between the IW and IC treatments during daytime, as well as during the time after the breakfast meal on day 1 ; however, the subjects tended to feel less comfortable after consumption of $\mathrm{HC}$ than after consumption of IW $(P=0.093)$.

\section{Discussion}

The present study showed that whey, casein and hydrolysed casein induced similar effects on appetite regulation and on $24 \mathrm{~h}$ total and postprandial EE after ingestion of high-protein mixed meals. However, we showed that the RQ value was lower after consumption of whey than after consumption of hydrolysed casein, also after adjustment for energy balance. This might indicate higher lipid oxidation after ingestion of whey than after ingestion of hydrolysed casein, which was supported by the response of NEFA concentration.

Proteins are more satiating than $\mathrm{CHO}$ and $\mathrm{fat}^{(2,3,30)}$, and Belza et $a l .{ }^{(1)}$ recently showed that proteins stimulate satiety in a dose-dependent manner. However, little is known about the effects of different protein sources. Proteins differ in their amino acid composition, which may influence their effects on satiety. Casein and whey are both complete proteins, but whey has a higher content of branch-chained amino acids and contains the components glycomacropeptide and $\alpha$-lactoglobulin, which have previously been found to stimulate satiety ${ }^{(31-33)}$. Despite this finding, there is no clear evidence that whey is more satiating than casein or vice versa $^{(8)}$. In the present study, no difference was observed between the whey, casein and hydrolysed casein treatments, which is supported by several human studies ${ }^{(16,32,34)}$. However, the results have been inconsistent. Hall et al. ${ }^{(9)}$ found that whey stimulates satiety compared with casein during $180 \mathrm{~min}$ following ingestion. Accordingly, they observed a higher plasma concentration of the appetite-regulating hormones cholecystokinin, GLP-1 and glucose-dependent insulinotropic polypeptide after consumption of whey. This finding is partly supported by Veldhorst et al. ${ }^{(15)}$, who demonstrated a decreased feeling of hunger after consumption of whey compared with casein at a protein dose of $10 \mathrm{E} \%$. However, they observed no difference at a dose of $25 \mathrm{E} \%$. They suggested that the inconsistent results may be explained by the difference in protein concentration, as the concentration of certain amino acids may need to be above a particular threshold to promote a relatively stronger hunger suppression or greater satiety. Their results suggested that certain proteins will reach these threshold concentrations at lower doses than other proteins. At high-protein loads, it may not be possible to distinguish between different complete proteins as the concentration of all amino acids rapidly increases above this threshold. In the present study, the percentage of energy from proteins varied from 17 to $26 \mathrm{E} \%$, suggesting that the protein load may be too high to detect a difference between the proteins. However, other factors may play a role. For example, Acheson et al. ${ }^{(3)}$ found that casein is more satiating than whey at a protein content of $50 \mathrm{E} \%$. They continued their measurements for $330 \mathrm{~min}$, which indicated that timing of measurements may also play an important role. In support, Boirie et al. ${ }^{(14)}$ showed that plasma amino acid concentrations are higher after consumption of whey than after consumption of casein at $100 \mathrm{~min}$ and higher after consumption of casein than after consumption of whey at $300 \mathrm{~min}$. This suggests that the effects of casein may not be fully developed when appetite measures are obtained shortly $(180 \mathrm{~min})$ after protein consumption as in the study by Hall et al. ${ }^{(9)}$, and that the concentration of amino acids after consumption of whey may have returned to baseline levels when the measurements are continued for $330 \mathrm{~min}$. Accordingly, we expected that whey and hydrolysed casein would have a greater satiating effect than casein shortly after protein consumption, and that casein would be more satiating several hours after consumption of proteins. Moreover, we expected that gastric emptying and the rate of absorption would influence the effect on EE in a similar way.

We observed no differences between the dietary proteins in relation to postprandial or $24 \mathrm{~h}$ total EE. In support of this finding, Lorenzen et al. ${ }^{(16)}$ also did not find a difference in DIT between whey and casein; however, the results have been inconsistent ${ }^{(3,17)}$. Previously it has been shown that when whey and casein are served in mixed meals, it may mask the differences in kinetics, mostly due to a slower absorption rate of whey ${ }^{(35)}$. Therefore, this may explain the reason why we observed no differences in appetite regulation and EE between the dietary proteins. Moreover, it can be speculated that the differences in kinetics may be masked by other proteins present in the shakes/meals. However, they only make up a very small amount of total protein $(2.7 \mathrm{E} \%$ of $26 \mathrm{E} \%$ in the shakes) and were also similar between the dietary treatments, why it is unlikely to affect the present results. However, other factors may play important roles such as those suggested by Acheson et al ${ }^{(3)}$ who found that consumption of whey induced a larger increase in DIT and cumulative $\mathrm{EE}$ at $330 \mathrm{~min}$ than consumption of casein, although the proteins were served as shakes that additionally contained fat and $\mathrm{CHO}$. The authors suggested that the higher DIT observed following consumption of whey may be explained by the beneficial effect on protein synthesis. Boirie et al. ${ }^{(14)}$ showed that protein synthesis was 2-fold more rapid, measured at 40-140 min, after consumption of 
whey than after consumption of casein. In contrast to the present study and the study by Lorenzen et al. ${ }^{(16)}$ where casein was served as a caseinate, in the study by Acheson et al. ${ }^{(3)}$, casein was served as micellar casein. Caseinates are absorbed more rapidly than the micellar form, which may explain why the difference in absorption rates between proteins used in the present study may be very small.

Furthermore, comparison of studies may be hampered by the use of different methodologies, timings of measurements, energy contents and proportions of protein in the meals served. The majority of studies investigating the effects of protein on EE have measured the thermogenic effect after one single meal using ventilated hood systems, whereas the present study used respiration chambers. It can be speculated that the 'dead space' of the chambers $\left(14.7 \mathrm{~m}^{3}\right)$ may be too large to allow the detection of small and transient changes in EE. However, respiration chambers were also used in the study by Acheson et al. $^{(3)}$, but these chambers may have very different response times. Moreover, as DIT is only $10 \%$ of the total EE, it can be speculated that a rather large meal is necessary to induce a detectable increase in postprandial EE. The meal size in the study by Acheson et al. ${ }^{(3)}$ was similar to the breakfast meal in the present study ( $20 \%$ of ER), but the protein content was much greater $(50 \mathrm{E} \%)$.

To our knowledge, no human studies have compared the effects of casein and its hydrolysate on EE or appetite regulation; however, a recent study in mice has shown that intact casein and hydrolysed casein induce similar effects on $\mathrm{EE}^{(20)}$. The authors also examined the effect on the RQ and showed that hydrolysed casein tends to induce a lower RQ than intact casein during light periods (07.30-19.00 hours), indicating that the absorption rate may play an important role. In the present study, no difference in RQ was found between hydrolysed casein and intact casein; however, we found that hydrolysed casein induced a slightly higher mean RQ value $(0.86$ (SEM 0.01) v. 0.84 (SEM 0.01), respectively) than whey during daytime when food was provided, and these results remained significant after adjustment for energy balance. A higher RQ value suggests higher $\mathrm{CHO}$ and lower lipid oxidation, but could also indicate higher amino acid oxidation, which would drive the $\mathrm{RQ}$ value to $0 \cdot 8^{(36)}$. A limitation of the present study was that there was no continuous measurement of protein oxidation. Only the data on the average $24 \mathrm{~h}$ protein oxidation were obtained from $24 \mathrm{~h}$ $\mathrm{N}$ excretion. However, data on the RQ and substrate oxidation were analysed over rather long postprandial time intervals ( $\geq 4.5 \mathrm{~h}$ post-meal consumption), and based on previous findings ${ }^{(14,18)}$, we expected that amino acids, from all the three dietary proteins, would be absorbed within this time period.

Furthermore, data on the RQ and substrate oxidation were supported by the response of plasma NEFA concentrations. NEFA concentrations were positively correlated with lipid oxidation and have previously been associated with a lower RQ value $^{(37)}$ and lower glucose oxidation ${ }^{(38)}$. In accordance with a lower RQ value after consumption of whey, the response of NEFA concentration was increased compared with hydrolysed casein. Furthermore, insulin is known to suppress lipolysis ${ }^{(39)}$. Therefore, it can be speculated that insulin may have a modulating effect on lipolysis and consequently lipid oxidation. In the present study, insulin was weakly correlated with lipid oxidation estimated from the RQ; however, we observed no differences in postprandial response of insulin concentration between the dietary proteins. Data on the differences in the insulinotropic effects of whey and casein in healthy human subjects are sparse; however, some studies have suggested a beneficial effect of whey ${ }^{(40,41)}$. Moreover, it has been previously demonstrated that the response of insulin concentration is associated with the availability of plasma amino acids ${ }^{(23,42)}$, with rapidly absorbed proteins inducing a greater response of insulin concentration than slowly absorbed proteins. Accordingly, Deglaire et al. ${ }^{(43)}$ showed a higher insulin response after ingestion of hydrolysed casein than after ingestion of casein, especially during the initial postprandial hours when plasma amino acids were higher.

In contrast, Akhavan et al. ${ }^{(21)}$ investigating the effects of intact and hydrolysed whey on glucose and insulin concentrations found that intact whey stimulates a lower postprandial glucose concentration than hydrolysed whey, despite similar insulin concentrations. This indicates that intact proteins regulate blood glucose levels in a non-insulinotropic manner. A higher blood glucose concentration following consumption of hydrolysed whey may stimulate a higher RQ value, which was not measured. This also suggests that gastric emptying may affect the magnitude and timing of postprandial blood glucose and insulin increases and that intact whey is emptied more slowly than hydrolysed whey because whey, but not hydrolysed whey, stimulates the secretion of gut peptides that are involved in glycaemic control and gastric emptying. This is though not a consistent finding. Calbet \& Holst ${ }^{(18)}$ showed that whey and casein, as well as their hydrolysates, stimulate the secretion of incretins. Likewise, we showed that at some time points, GLP-1 concentrations were higher after consumption of hydrolysed casein than after consumption of intact casein and intact whey. In contrast, there was no overall difference in GLP-1 concentration between the dietary proteins, which is in accordance with the data on insulin and appetite regulation. Data from previous studies investigating the effect of different protein sources are inconsistent ${ }^{(9,18,44)}$. For example, Hall et al. ${ }^{(9)}$ observed an increase in GLP-1 concentration after consumption of whey than after consumption of casein in accordance with a greater satiating effect, whereas Calbet \& Holst ${ }^{(18)}$ showed no difference in GLP-1 response between whey, casein and their hydrolysates. Finally, we observed a higher mean glucose concentration after consumption of casein than after consumption of hydrolysed casein, although there was no difference in insulin concentration. This may, however, be a matter of chance finding due to multiple testing.

The strength of the present study was the randomised crossover design, where the subjects were kept under controlled settings for $40 \mathrm{~h}$, including the measurements. Moreover, proteins were served in mixed meals, which reflect real-life situations, and measurements were continued for a total $24 \mathrm{~h}$ period. However, the study has also some obvious limitations. As mentioned previously, protein oxidation was not assessed as a function of time, and fat and $\mathrm{CHO}$ oxidation were not independently tested but estimated from the RQ values. 
Moreover, gastric emptying and differences in absorption rates were not measured. Finally, as shown in Fig. 4, a blood sample taken at $45 \mathrm{~min}$ would have been advantageous as all biochemical measures were likely to reach peak or nadir magnitude between 30 and $60 \mathrm{~min}$. Therefore, the lack of the blood sample taken at this time period limits the analyses of peak and nadir magnitudes.

\section{Conclusion}

In conclusion, data from the present study suggest that repeated meals with whey, hydrolysed casein and casein induce similar effects on appetite regulation and postprandial and total EE over $24 \mathrm{~h}$, which may be explained by similar absorption rates when proteins are served as high-protein mixed meals. However, we found that whey resulted in a slightly lower RQ value than hydrolysed casein, indicating a potentially higher lipid oxidation and lower $\mathrm{CHO}$ oxidation. Future studies are needed to investigate whether the effects on substrate oxidation can be verified and whether they persist over time, and thereby can contribute to a beneficial effect on body weight. Moreover, future studies should focus on the effect of the relative amount of protein in the meals served, and the effect of serving protein in mixed meals $v$. the effect of serving proteins alone, as this may influence gastric emptying and the rate of absorption.

\section{Acknowledgements}

The authors are grateful to the laboratory and kitchen staff at the department for their assistance, especially Jane Jørgensen, Søren Andresen, John Lind, Lene Stevner, Yvonne Fatum and Charlotte Kostecki. They especially thank Sisse Gomes, Jan la Cour Lindboe, Sofia Wannbäck and Mostafa Jafar for their help during the practical work.

The present study was sponsored by a grant from the Ministry of Science, Technology and Innovation, Denmark; Arla Foods Ingredients Group P/S, Denmark; and the Danish Dairy Research Foundation, Denmark. Proteins were supplied by FrieslandCampina Domo EMEA, The Netherlands; Arla Foods Amba, Denmark; and Arla Foods Ingredients, Denmark. The sponsors were not involved in the design of the study, in the collection, analysis and interpretation of the data or in the writing of this article.

The authors' contributions are as follows: L. Q. B., J. K. L., B. L. and A. A. designed the research; L. Q. B., J. K. L. and S. G. conducted the research; L. Q. B., S. G., J. J. H., S. R. and C. R. analysed the data; L. Q. B. and A. S. drafted the manuscript; J. K. L., S. G., B. L., S. R., C. R., J. J. H. and A. A. co-edited and revised the manuscript critically for important intellectual content; L. Q. B. had the primary responsibility for the final content. All authors read and approved the final manuscript.

A. A. is currently the member of the advisory board for Global Dairy Platform, USA. He is the member of the Arla $\mathrm{A} / \mathrm{S}$ - Copenhagen University steering group. Over the past 5 years, his research has received funding from Arla Foods $\mathrm{A} / \mathrm{S}$ and the Danish Dairy Association, and from international dairy interests contributing to a collaborative grant coordinated by Global Dairy Platform. The rest of the authors declare that there are no conflicts of interest.

\section{References}

1. Belza A, Ritz C, Sorensen MQ, et al. (2013) Contribution of gastroenteropancreatic appetite hormones to proteininduced satiety. Am J Clin Nutr 97, 980-989.

2. Astrup A (2005) The satiating power of protein - a key to obesity prevention? Am J Clin Nutr 82, 1-2.

3. Acheson $\mathrm{KJ}$, Blondel-Lubrano A, Oguey-Araymon $\mathrm{S}$, et al (2011) Protein choices targeting thermogenesis and metabolism. Am J Clin Nutr 93, 525-534.

4. Larsen TM, Dalskov SM, van Baak M, et al. (2010) Diets with high or low protein content and glycemic index for weightloss maintenance. N Engl J Med 363, 2102-2113.

5. Skov AR, Toubro S, Ronn B, et al. (1999) Randomized trial on protein $v s$ carbohydrate in ad libitum fat reduced diet for the treatment of obesity. Int J Obes Relat Metab Disord 23, 528-536.

6. Weigle DS, Breen PA, Matthys CC, et al. (2005) A highprotein diet induces sustained reductions in appetite, ad libitum caloric intake, and body weight despite compensatory changes in diurnal plasma leptin and ghrelin concentrations. Am J Clin Nutr 82, 41-48.

7. Gilbert JA, Bendsen NT, Tremblay A, et al. (2011) Effect of proteins from different sources on body composition. Nutr Metab Cardiovasc Dis 21, Suppl. 2, B16-B31.

8. Bendtsen LQ, Lorenzen JK, Bendsen NT, et al. (2013) Effect of dairy proteins on appetite, energy expenditure, body weight, and composition: a review of the evidence from controlled clinical trials. Adv Nutr 4, 418-438.

9. Hall WL, Millward DJ, Long SJ, et al. (2003) Casein and whey exert different effects on plasma amino acid profiles, gastrointestinal hormone secretion and appetite. Br J Nutr 89, $239-248$

10. Pal S \& Ellis V (2010) The acute effects of four protein meals on insulin, glucose, appetite and energy intake in lean men. Br J Nutr 104, 1241-1248.

11. Mikkelsen PB, Toubro S \& Astrup A (2000) Effect of fat-reduced diets on 24-h energy expenditure: comparisons between animal protein, vegetable protein, and carbohydrate. Am J Clin Nutr 72, 1135-1141.

12. Abargouei AS, Janghorbani M, Salehi-Marzijarani M, et al. (2012) Effect of dairy consumption on weight and body composition in adults: a systematic review and meta-analysis of randomized controlled clinical trials. Int J Obes (Lond) $\mathbf{1 7}$, $1-9$.

13. Chen M, Pan A, Malik VS, et al. (2012) Effects of dairy intake on body weight and fat: a meta-analysis of randomized controlled trials. Am J Clin Nutr 96, 735-747.

14. Boirie Y, Dangin M, Gachon P, et al. (1997) Slow and fast dietary proteins differently modulate postprandial protein accretion. Proc Natl Acad Sci U S A 94, 14930-14935.

15. Veldhorst MA, Nieuwenhuizen AG, Hochstenbach-Waelen A, et al. (2009) Dose-dependent satiating effect of whey relative to casein or soy. Physiol Behav 96, 675-682.

16. Lorenzen J, Frederiksen R, Hoppe C, et al. (2012) The effect of milk proteins on appetite regulation and diet-induced thermogenesis. Eur J Clin Nutr 66, 622-627.

17. Alfenas RCG, Bressan J \& Paiva AC (2010) Effects of protein quality on appetite and energy metabolism in normal weight subjects. Arq Bras Endocrinol Metabol 54, 45-51. 
18. Calbet JA \& Holst JJ (2004) Gastric emptying, gastric secretion and enterogastrone response after administration of milk proteins or their peptide hydrolysates in humans. Eur J Nutr 43, 127-139.

19. Koopman R, Crombach N, Gijsen AP, et al. (2009) Ingestion of a protein hydrolysate is accompanied by an accelerated in vivo digestion and absorption rate when compared with its intact protein. Am J Clin Nutr 90, 106-115.

20. Lillefosse HH, Tastesen HS, Du ZY, et al. (2013) Hydrolyzed casein reduces diet-induced obesity in male $\mathrm{C} 57 \mathrm{BL} / 6 \mathrm{~J}$ mice. J Nutr 143, 1367-1375.

21. Akhavan T, Luhovyy BL, Brown PH, et al. (2010) Effect of premeal consumption of whey protein and its hydrolysate on food intake and postmeal glycemia and insulin responses in young adults. Am J Clin Nutr 91, 966-975.

22. Anderson GH, Tecimer SN, Shah D, et al. (2004) Protein source, quantity, and time of consumption determine the effect of proteins on short-term food intake in young men. J Nutr 134, 3011-3015.

23. Morifuji M, Ishizaka M, Baba S, et al. (2010) Comparison of different sources and degrees of hydrolysis of dietary protein: effect on plasma amino acids, dipeptides, and insulin responses in human subjects. J Agric Food Chem 58, 8788-8797.

24. Cunningham JJ (1991) Body composition as a determinant of energy expenditure: a synthetic review and a proposed general prediction equation. Am J Clin Nutr 54, 963-969.

25. Astrup A, Thorbek G, Lind J, et al. (1990) Prediction of 24-h energy expenditure and its components from physical characteristics and body composition in normal-weight humans. Am J Clin Nutr 52, 777-783.

26. Elia M \& Livesey G (1992) Energy expenditure and fuel selection in biological systems: the theory and practice of calculations based on indirect calorimetry and tracer methods. World Rev Nutr Diet 70, 68-131.

27. Orskov C, Rabenhoj L, Wettergren A, et al. (1994) Tissue and plasma concentrations of amidated and glycine-extended glucagon-like peptide I in humans. Diabetes 43, 535-539.

28. Hochstenbach-Waelen A, Veldhorst MA, Nieuwenhuizen AG et al. (2009) Comparison of 2 diets with either $25 \%$ or $10 \%$ of energy as casein on energy expenditure, substrate balance, and appetite profile. Am J Clin Nutr 89, 831-838.

29. Hochstenbach-Waelen A, Westerterp-Plantenga MS, Veldhorst MA, et al. (2009) Single-protein casein and gelatin diets affect energy expenditure similarly but substrate balance and appetite differently in adults. J Nutr 139, 2285-2292.

30. Westerterp KR (2004) Diet induced thermogenesis. Nutr Metab (Lond) 1, 5 .

31. Veldhorst MA, Nieuwenhuizen AG, Hochstenbach-Waelen A, et al. (2009) Effects of complete whey-protein breakfasts versus whey without GMP-breakfasts on energy intake and satiety. Appetite 52, 388-395.

32. Veldhorst MA, Nieuwenhuizen AG, Hochstenbach-Waelen A, et al. (2009) A breakfast with $\alpha$-lactalbumin, gelatin, or gelatin + TRP lowers energy intake at lunch compared with a breakfast with casein, soy, whey, or whey-GMP. Clin Nutr 28, 147-155.

33. Hursel R, van der Zee L \& Westerterp-Plantenga MS (2010) Effects of a breakfast yoghurt, with additional total whey protein or caseinomacropeptide-depleted $\alpha$-lactalbuminenriched whey protein, on diet-induced thermogenesis and appetite suppression. Br J Nutr 103, 775-780.

34. Bowen J, Noakes M, Trenerry C, et al. (2006) Energy intake, ghrelin, and cholecystokinin after different carbohydrate and protein preloads in overweight men. J Clin Endocrinol Metab 91, 1477-1483.

35. Dangin M, Guillet C, Garcia-Rodenas C, et al. (2003) The rate of protein digestion affects protein gain differently during aging in humans. J Physiol 549, 635-644.

36. Weir JB (1949) New methods for calculating metabolic rate with special reference to protein metabolism. J Physiol 109, 1-9.

37. Toubro S, Sorensen TI, Hindsberger C, et al. (1998) Twentyfour-hour respiratory quotient: the role of diet and familial resemblance. J Clin Endocrinol Metab 83, 2758-2764.

38. Roden M, Price TB, Perseghin G, et al. (1996) Mechanism of free fatty acid-induced insulin resistance in humans. J Clin Invest 97, 2859-2865.

39. Nurjhan N, Campbell PJ, Kennedy FP, et al. (1986) Insulin dose-response characteristics for suppression of glycerol release and conversion to glucose in humans. Diabetes $\mathbf{3 5}$, $1326-1331$.

40. Holmer-Jensen J, Mortensen LS, Astrup A, et al. (2013) Acute differential effects of dietary protein quality on postprandial lipemia in obese non-diabetic subjects. Nutr Res 33, 34-40.

41. Gunnerud U, Holst JJ, Ostman E, et al. (2012) The glycemic, insulinemic and plasma amino acid responses to equicarbohydrate milk meals, a pilot-study of bovine and human milk. Nutr J 11, 83.

42. Gunnerud UJ, Ostman EM \& Bjorck IM (2013) Effects of whey proteins on glycaemia and insulinaemia to an oral glucose load in healthy adults; a dose-response study. Eur J Clin Nutr 67, 749-753.

43. Deglaire A, Fromentin C, Fouillet H, et al. (2009) Hydrolyzed dietary casein as compared with the intact protein reduces postprandial peripheral, but not whole-body, uptake of nitrogen in humans. Am J Clin Nutr 90, 1011-1022.

44. Nilsson M, Stenberg M, Frid AH, et al. (2004) Glycemia and insulinemia in healthy subjects after lactose-equivalent meals of milk and other food proteins: the role of plasma amino acids and incretins. Am J Clin Nutr 80, 1246-1253. 